\title{
Free and bound choline blood levels after phosphatidylcholine
}

\begin{abstract}
In six normal subjects we investigated the effects of oral phosphatidylcholine (lecithin) on the concentrations of plasma choline, erythrocyte choline, and choline-containing lipids. Plasma choline levels rose I hr after treatment and remained elevated for $8 \mathrm{hr}$, with peaks at 3 and $4 \mathrm{hr}$ after phosphatidylcholine. Erythrocyte choline levels also rose, although the rise was slightly delayed relative to plasma choline. There was no change in the plasma choline-containing lipid concentration. These results demonstrate that, in normal subjects, oral phosphatidylcholine induces prolonged rises in plasma and erythrocyte choline concentrations and is therefore useful when such effects are desired.
\end{abstract}

\author{
Richard S. Jope, Ph.D., Edward F. Domino, M.D., Benjamin N. Mathews, M.S., \\ Natraj Sitaram, M.D., Donald J. Jenden, M.D., and Aurelio Ortez, M.D. \\ Los Angeles, Calif., and Detroit and Ann Arbor, Mich. \\ Department of Pharmacology and The Brain Research Institute, School Medicine, University of \\ California, Los Angeles, Department of Pharmacology and Affective Disorders Unit, Lafayette \\ Clinic, and Department of Psychiatry, Wayne State University, Detroit, and Department of \\ Pharmacology, University of Michigan, Ann Arbor
}

Clinical and laboratory research in the field of central nervous system cholinergic pharmacology has been seriously hampered by the lack of a long-lasting cholinomimetic agent that is active in the brain. Based on the contention that increased levels of choline will increase the concentration of choline in the brain since the choline transport system across the blood brain barrier ( $\mathrm{K}_{\mathrm{T}}$ approximately $\left.440 \mu \mathrm{M}\right)$ is not saturated by the normal plasma choline concentration of 10 to $20 \mu \mathrm{M},{ }^{6}$ Haubrich et al ${ }^{10}$ and Wurtman et al..$^{5,20}$ suggested the use of large

\footnotetext{
Supported by grant MH-17691 (DJJ) and the Psychopharmacology Research Fund (EFD), and the Michigan Department of Mental Health.

Received for publication May 15, 1981.

Accepted for publication Nov. 20, 1981.

Reprint requests to: Dr. Richard Jope, Department of Pharmacology, School of Medicine, University of California, Los Angeles, CA 90024.
}

doses of choline to promote acetylcholine (ACh) synthesis. Systemic administration of choline may lead to a rise in choline levels in the brain, ${ }^{5,10}$ but a resultant elevation in levels and utilization of $\mathrm{ACh}$ is controversial (for review, see Jenden ${ }^{14}$ ).

Recently choline has been partially superseded by the use of phosphatidylcholine* (PCh), which does not give rise to the strong "fishy" odor obtained after choline treatment. ${ }^{4,}{ }^{11}$ PCh has been reported to be beneficial in patients with tardive dyskinesia ${ }^{8,} 22$ and is undergoing clinical evaluation in a number of other diseases. ${ }^{2-4,7}, 18,19$ Since the clinical use of the

\footnotetext{
*Although the term lecithin has recently been used in reports of investigations of phosphatidylcholine therapy, lecithin has long been used to indicate an impure mixture of phosphatides. We therefore use phosphatidyl to more accurately identify the compound under investigation.
} 

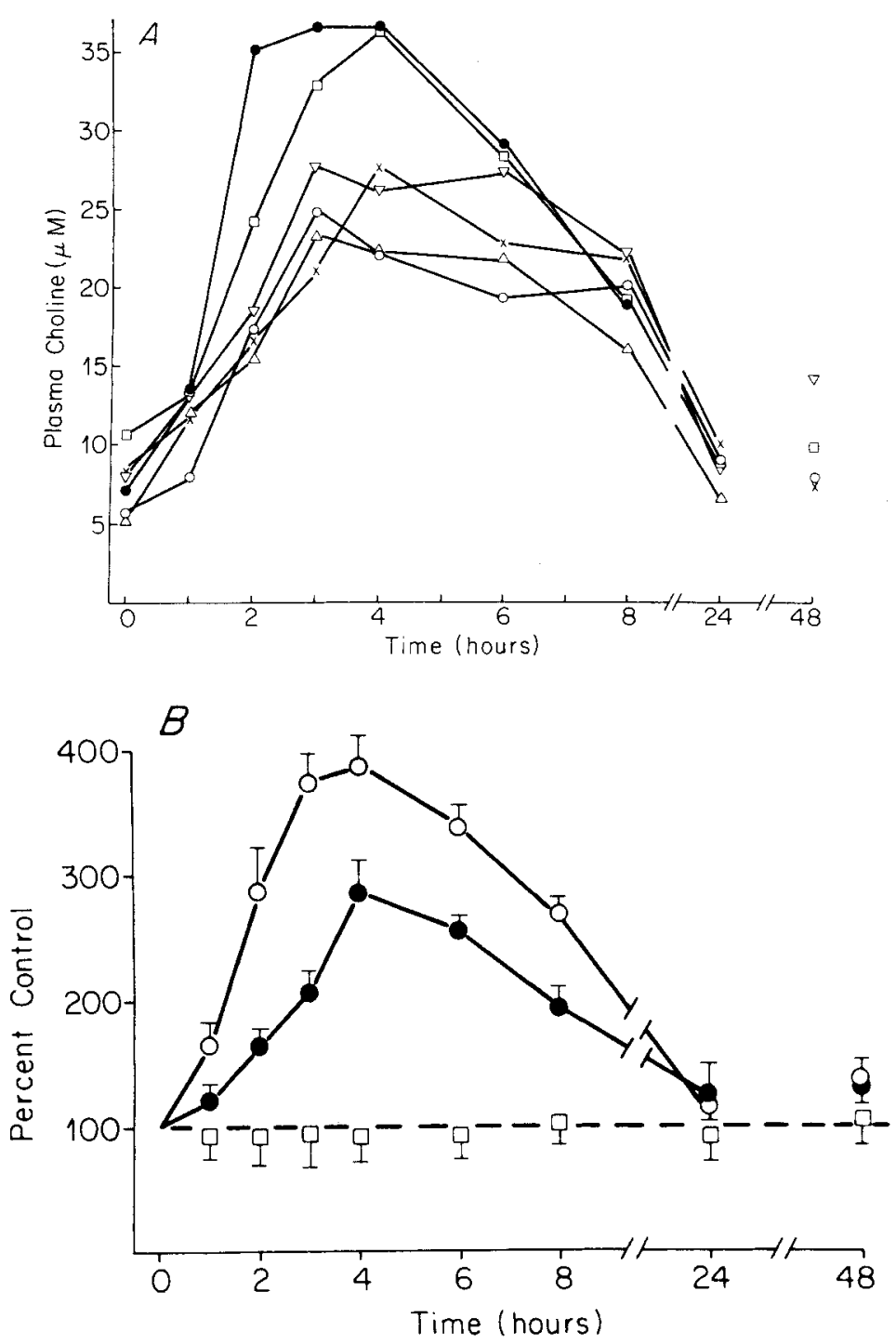

Fig. 1. $A$, Plasma choline concentration. $B$, Average percent changes in plasma choline ( 0 ), plasma lipid bound choline ( $\square$ ), and erythrocyte choline $(\bullet)$ obtained from six normal subjects after oral PCh ( $15 \mathrm{gm} / 70 \mathrm{~kg}$ body weight). The initial plasma choline, erythrocyte choline, and plasma lipid bound choline concentrations were $7.4 \pm 2.0,15.3 \pm 4.9$, and $996 \pm 234(\bar{x} \pm$ SD).

drug is expanding rapidly, we studied the PCh kinetics in six normal subjects. Wurtman et al. ${ }^{21}$ and Hirsch et al. ${ }^{12}$ reported that human consumption of a meal supplemented with $100 \mathrm{gm}$ of impure PCh granules (equivalent to $2.3 \mathrm{gm}$ choline) increased serum choline concentration. This effect was reported to last for at least $12 \mathrm{hr}$, at which time serum choline was at its highest level. ${ }^{12,}{ }^{21}$ More recently Zeisel et al ${ }^{23}$ reported that $25 \mathrm{gm}$ of $80 \%$ pure $\mathrm{PCh}$ quadrupled plasma choline concentration with a peak level at approximately $5 \mathrm{hr}$ after treatment. We report here the effects of PCh consumption by normal subjects on plasma choline, erythrocyte choline, and choline-containing lipids in the plasma. Since this pool may also be a precursor of brain choline and $\mathrm{ACh},{ }^{1,15}$ choline-containing lipids were measured to determine whether consumption of a large amount of PCh altered the release of lipid bound choline into the blood. Eryth- 
rocyte choline was measured as an index of changes of the choline concentration in an intracellular pool, and also because it has been shown to rise after lithium ${ }^{16}$ and in some patients with affective disorders. ${ }^{9,16}$

\section{Materials and methods}

Six subjects were studied. Each took 15 $\mathrm{gm} / 70 \mathrm{~kg}$ body weight (total dose $=11.1$ to $16.7 \mathrm{gm}$ PCh) Phospholipon-100 (approximately 94\% PCh; American Lecithin) at 8:00 to 9:00 A.M. after an overnight fast. The PCh was suspended in $0.45 \% \mathrm{NaCl}$ and consumption was followed by a small amount of milk. After the 2-hr blood sample the subjects ate a breakfast of orange juice, coffee or tea, and two slices of toast with jam and a pat of butter. After the 4-hr blood sample was drawn the subjects ate a lunch with low PCh content.

At the indicated times blood was drawn into a heparinized syringe and centrifuged at $4^{\circ}$ at $3000 \mathrm{~g}$ for $5 \mathrm{~min}$. Choline in the plasma and erythrocytes was extracted in $15 \% 1 \mathrm{~N}$ formic acid in acetone ( $\mathrm{v} / \mathrm{v})$ that contained precisely known quantities of $\left[{ }^{2} \mathrm{H}_{9}\right]$-choline as internal standard. Choline-containing lipids in the plasma were extracted in $20 \mathrm{vol} \mathrm{CHCl}_{3}: \mathrm{MeOH}$ (2:1) containing $\left[{ }^{2} \mathrm{H}_{9}\right]-\mathrm{PCh}$ as internal standard. $\left[{ }^{2} \mathrm{H}_{9}\right]$-PCh was labeled in the choline moiety by predeuteration of the methyl groups. Free choline was hydrolyzed from the lipids by incubation in $1 \mathrm{~N} \mathrm{KOH}$ for $1 \mathrm{hr}$ at $95^{\circ}$. Choline was isolated by ion-pair extraction with dipicrylamine into dichloromethane and measured by gas chromatography-mass spectrometry as previously described.${ }^{14}$ Choline was also measured by gas chromatography using a nitrogen detector with homocholine (3-hydroxypropyltrimethylammonium iodide) as the internal standard after extraction as described by Kosh et al. ${ }^{17}$ The results of the two assays were almost identical with correlation coefficients of 0.98 for choline in both plasma and erythrocytes.

\section{Results}

Oral doses of $15 \mathrm{gm} \mathrm{PCh} / 70 \mathrm{~kg}$ body weight increased plasma choline concentrations to levels three to four times those before treatment (Fig. 1, $A$ ). Increased concentrations were apparent $1 \mathrm{hr}$ after treatment in all subjects.

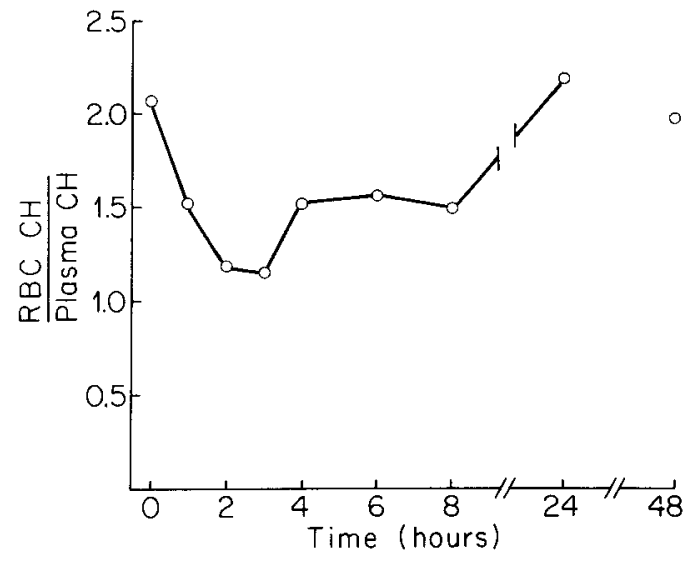

Fig. 2. Average ratios of erythrocyte choline to plasma choline in six subjects after oral administration of PCh (15 gm/70 kg body weight).

Plasma choline levels peaked between 3 and 4 $\mathrm{hr}$ after PCh. The duration of the peak plasma choline level varied among the subjects, e.g., in two subjects there was a well-defined peak while in two others there was a plateau between 3 and $8 \mathrm{hr}$ after treatment. Plasma choline concentrations were near normal, although still slightly elevated, $24 \mathrm{hr}$ after treatment.

Erythrocyte choline concentrations rose in approximate parallel to the rise in plasma choline (Fig. 1, B), but the increase of choline in erythrocytes was delayed relative to the plasma choline and reached maximum concentrations between 4 and $6 \mathrm{hr}$ after PCh. The results from one subject were omitted from the calculations because his initial erythrocyte choline concentration was $170 \mu \mathrm{M}$, approximately 10 times that of the other subjects. The high erythrocyte choline level was confirmed in a repeat determination 1 mo later. The cause of this abnormally high level is under investigation.

The ratio of the choline concentration in erythrocytes to that in plasma is shown in Fig. 2. This indicates that, although the intracellular erythrocyte choline concentration rose, it did not do so to the same extent as plasma choline.

Lipid bound choline in the plasma did not change after PCh (Fig. 1, B).

\section{Discussion}

These results demonstrate that, in man, $\mathrm{PCh}$ raises plasma choline concentration for a longer 
period than an equimolar dose of choline. The only side effect noted was mild nausea in two subjects approximately $6 \mathrm{hr}$ after treatment. The extended effect of, and minimal side effects attributed to, PCh suggest that it is clinically preferable to choline as a means of elevating plasma choline levels.

The only cell easily accessible for measuring intracellular choline concentration in man is the erythrocyte. $\mathrm{PCh}$ induced prolonged elevation of erythrocyte choline concentration to much the same extent as plasma choline. This is presumably a direct result of the increased plasma choline concentration since the erythrocyte has a transport system with a relatively low affinity for choline $(40 \mu \mathrm{M})$ that is not saturated by the normal plasma choline concentration of approximately $10 \mu \mathrm{M}$. These results in erythrocytes indicate that at least one intracellular pool of choline increases after PCh. As shown in Fig. 2 , however, the intracellular erythrocyte choline concentration did not rise to the same degree as plasma choline. The ratio of erythrocyte choline to the plasma choline level may be a useful index for monitoring intracellular choline changes after PCh or choline. The blood brain barrier also has a low affinity for choline $\left(\mathrm{K}_{\mathrm{T}}=\right.$ $440 \mu \mathrm{M}$ ) so that choline transport from the plasma into the brain should also be increased by PCh treatment. ${ }^{6}$ Whether or not increased brain choline will alter the activity of cholinergic neurons remains to be determined. Although this hypothesis remains unresolved, choline loading may have a greater effect in pathologic states where there is evidence of cholinergic hypofunction. The beneficial effects of PCh therapy reported ${ }^{4}$ and the prolonged increase in choline levels, with minimal side effects, following PCh suggest that it is a drug of choice for promoting cholinergic function by precursor loading.

We would like to acknowledge the excellent technical assistance of Franz Fucek, Sandra Demetiou, Diane Ruffing, Sandi Tait, and Esther Shaw.

\section{References}

1. Ansell GB, Spanner S.: The source of choline for acetylcholine synthesis, in Jenden DJ, editor: Cholinergic mechanisms and psychopharmacology. New York, 1977, Plenum Press, pp. 431445 .
2. Barbeau A: Lecithin in movement disorders, in Barbeau A, Growdon J, Wurtman R, editors: Nutrition and the brain. New York, 1979, Raven Press, vol. V, pp. 263-272.

3. Barbeau, A.: Cholinergic treatment in the Tourette syndrome. $\mathrm{N}$ Engl J Med 302:1310-1311, 1980.

4. Barbeau A, Growdon J, Wurtman R, editors: Nutrition and the brain. New York, 1979, Raven Press, vol. V.

5. Cohen E, Wurtman R: Brain acetylcholine synthesis: Control by dietary choline. Science 191: 561-562, 1976.

6. Cornford EM, Braun LD, Oldendorf WH: Carrier mediated blood-brain barrier transport of choline and certain choline analogs. J Neurochem 30:299-308, 1978.

7. Etienne P, Gauthier S, Dastoor D: Alzheimer's disease: Clinical effect of lecithin therapy, in Barbeau A, Growdon J, Wurtman R, editors: Nutrition and the brain. New York, 1979, Raven Press, vol. V, pp. 389-398.

8. Growdon JH, Gelenberg AJ, Doller J, Hirsch MJ, Wurtman RJ: Lecithin can suppress tardive dyskinesia. N Engl J Med 298: 1029-1030, 1978.

9. Hanin I, Kopp U, Spiker DG, Neil JF, Shaw DH, Kupfer DJ: RBC and plasma choline levels in control and depressed individuals: A critical evaluation. Psychiatr Res 3:345-356, 1980.

10. Haubrich D, Wedeking PW, Wang PFL: Increase in tissue concentration of acetylcholine in guinea pigs in vivo induced by administration of choline. Life Sci 14:921-927, 1974.

11. Hirsch MJ, Wurtman RJ: Lecithin consumption inreases acetylcholine concentrations in rat brain and adrenal gland. Science 202:223-225, 1978.

12. Hirsch MJ, Growdon JH, Wurtman RJ: Relations between dietary choline or lecithin intake, serum choline levels and various metabolic indices. Metabolism 27:953-960, 1978.

13. Jenden DJ: The neurochemical basis of acetylcholine precursor loading as a therapeutic strategy, in Davis KC, Berger PA, editors: Brain acetylcholine and neuropsychiatric disease. New York, 1979, Plenum Press.

14. Jenden DJ, Roch M, Booth RA: Simultaneous measurement of endogenous and deuterium labelled tracer variants of choline and acetylcholine in subpicomole quantities by gas chromatography mass spectrometry. Anal Biochem 55: 438-448, 1973.

15. Jope RS, Jenden DJ: Choline and phospholipid metabolism and the synthesis of acetylcholine in rat brain. J Neurosci Res 4:69-82, 1979.

16. Jope RS, Jenden DJ, Ehrlich BE, Diamond JE, Gosenfeld LF: Erythrocyte choline concentrations are elevated in manic patients. Proc Nat1 Acad Sci USA 77:6144-6146, 1980.

17. Kosh JW, Smith MB, Solwell JW, Freeman JJ: Improvements in the gas chromatographic anal- 
ysis of acetylcholine and choline. J Chromatogr 163:206-211, 1979.

18. Melancon SB, Fontaine G, Geoffroy G, Vanasse M, Dollaire L, Potier M: Correlation between serum lipoamide dehydrogenase activity and phosphotidylcholine therapy in Friedreich's ataxia. Can J Neurol Sci 7:413-416, 1980.

19. Polinsky RJ, Ebert MH, Caine ED, Ludlow C, Bassich CJ: Cholinergic treatment in the Tourette syndrome. N Engl J Med 302:1310, 1980.

20. Wurtman RJ, Fernstrom JD: Control of brain neurotransmitter synthesis by precursor availability and nutritional state. Biochem Pharmacol 25: 1691-1696, 1976.
21. Wurtman RJ, Hirsch MJ, Growdon JH: Lecithin consumption raises serum free choline levels. Lancet 2:68-69, 1977.

22. Zeisel SH, Gelenberg AJ, Growdon JH, Wurtman RJ: Use of choline and lecithin in the treatment of tardive dyskinesia, in Cattabeni F, Racagni G, Spano PF, Costa E, editors: Advances in biochemical psychopharmacology. New York, 1980, Raven Press.

23. Zeisel SH, Growdon JH, Wurtman RJ, Magil SG, Logue M: Normal plasma choline responses to ingested lecithin. Neurology 30:1226-1229, 1980. 